\title{
Microbial consumption and production of volatile organic compounds at the soil-litter interface
}

\author{
Kelly S. Ramirez • Christian L. Lauber • \\ Noah Fierer
}

Received: 17 August 2009/Accepted: 13 November 2009/Published online: 4 December 2009

(C) Springer Science+Business Media B.V. 2009

\begin{abstract}
Substantial amounts of volatile organic compounds (VOCs) can be released during decomposition and these compounds can affect atmospheric chemistry, belowground processes, and the structure of microbial communities in litter and soil. However, we have a limited understanding of the types, quantities and ecological impacts of VOCs emitted from litter. Here we used a closed flow-through system and proton transfer reaction mass spectrometry (PTR-MS) to characterize VOC emissions from soil and two litter types (Pinus taeda and Acer rubrum) over a 72-day incubation period. Microbial respiration rates were measured throughout the incubation, and the soils were harvested at the end of the incubation to determine how litter VOCs influenced soil $\mathrm{C}$ dynamics, $\mathrm{N}$ mineralization rates, and bacterial communities. Using the PTR-MS we identified over 100 VOCs, with 10 VOCs making up the majority of emissions. VOCs accounted for up to $2.5 \%$ of the C flux from litter. Soil was a net sink of litter VOCs, absorbing up to $80 \%$ of VOCs released
\end{abstract}

K. S. Ramirez $(\bowtie) \cdot$ N. Fierer

Department of Ecology and Evolutionary Biology,

University of Colorado, UCB 334, Boulder,

CO 80309-0334, USA

e-mail: kelly.ramirez@colorado.edu

C. L. Lauber · N. Fierer

Cooperative Institute for Research in Environmental Sciences, University of Colorado, UCB 216, Boulder, CO 80309, USA by litter, and exposure of soil to litter VOCs increased microbial respiration rates in soil by up to $15 \%$. However, we observed negligible impacts of litter VOCs on soil nutrient levels and bacterial community structure, suggesting that soils must be exposed to higher concentrations of VOCs than observed in our study, to cause effects on these soil characteristics. Overall, VOCs appear to have an important influence on $\mathrm{C}$ dynamics at the soil-litter interface and VOC emissions from decomposing litter may represent an understudied component of biosphere-atmosphere interactions.

Keywords Litter decomposition - Microbial ecology $\cdot$ Plant-soil interactions $\cdot$ Soil $\mathrm{CO}_{2}$ dynamics $\cdot$ VOC $\cdot$ Volatile organic compounds

\section{Introduction}

There is a large body of literature focusing on the dynamics of VOCs in the atmosphere and the role of these VOCs in atmospheric chemistry. Likewise, VOC production from living plants has been extensively studied and it is well documented that plants represent an important source of chemically reactive VOCs in the atmosphere (Monson and Holland 2003; Kesselmeier and Staudt 1999). There has been far less attention focused on VOC emissions from soil and litter even though they may also represent 
important terrestrial sources of VOCs (Stotzky and Schenck 1976; Cleveland and Yavitt 1998; Monson 2002; Asensio et al. 2007; Leff and Fierer 2008). In particular, VOC emissions from decomposing litter can be significant (Warneke et al. 1999; Schade and Crutzen 1999; Leff and Fierer 2008), yet the fate of such VOCs remains ambiguous. Many of the VOCs may freely diffuse into the atmosphere where they can impact global VOC inventories (Monson 2002). Yet, depending on conditions and the particular VOC type, litter-derived VOCs may have relatively low exchange rates with the atmosphere and could potentially influence soil microbial processes and characteristics at the soil-litter interface (Asensio et al. 2007; Owen et al. 2007). However, we currently have a limited understanding of belowground VOC dynamics. More specifically, VOC emissions from soil and litter have not been well-characterized and the extent to which these VOCs may influence biogeochemical processes and biotic interactions within soil has not been adequately resolved.

VOCs released from soil and litter can be derived from abiotic processes (Warneke et al. 1999), but most of the compounds emitted are likely to be products of root or microbial metabolism (Mackie and Wheatley 1999; Bunge et al. 2008; Mayrhofer et al. 2006). In particular, bacteria and fungi produce a wide range of VOCs when grown in pure culture (Mackie and Wheatley 1999; Wheatley 2002) and when actively metabolizing organic matter in litter and soil (Stotzky and Schenck 1976; Stahl and Parkin 1996; Mayrhofer et al. 2006; Amaral and Knowles 1998; Mackie and Wheatley 1999). Some of the most common types of VOCs emitted from soils and litters include methanol, monoterpenes, alcohols, and ethers (Stotzky and Schenck 1976; Leff and Fierer 2008), but the types and quantities of VOCs released during microbial decomposition are highly variable and influenced by both substrate type (e.g. litter chemistry) (Wheatley et al. 1997; Isidorov and Jdanova 2002) and microbial community composition (Stahl and Parkin 1996). VOCs released by decomposition processes can have a range of effects on soil processes and biotic interactions.

VOCs may act also as a carbon source for microorganisms, increasing soil $\mathrm{CO}_{2}$ production and decreasing nitrogen mineralization rates (Paavolainen et al. 1998; Mackie and Wheatley 1999; Amaral and Knowles 1997). For example, laboratory incubations of soil with high concentrations of VOCs often results in increases in respiration rates and microbial biomass, indicating a portion of the microbial community is capable of utilizing VOCs as a nutrient source (Paavolainen et al. 1998). Likewise, Owen et al. (2007) demonstrated in the field that rhizosphere bacteria are capable of VOC catabolism by isotopically labeled monoterpenes. Conversely, certain VOCs have been shown to interfere with specific microbial processes by inhibiting bacterial ammonium monooxygenase (AMO) (White 1988; Paavolainen et al. 1998) and methane monooxygenase (MMO) (Amaral and Knowles 1997), reducing the overall rates of nitrification and methane oxidation in soil. VOCs can also regulate bacterial growth rates (either stimulation or inhibition) via other mechanisms that remain undetermined (Mayrhofer et al. 2006; Mackie and Wheatley 1999; Wheatley et al. 1996).

The goal of this study was to identify the specific VOCs released during the decomposition of two litter types and to determine the potential for these litter VOCs to act as a carbon source for soil microorganisms. In order to expose soils to concentrations of VOCs similar to what would be observed in the field, we used a dynamic flow-through system with soils and decomposing litters sharing the microcosm headspace. $\mathrm{CO}_{2}$ and VOC concentrations were measured to determine if soil microorganisms were capable of mineralizing VOCs emitted from the decomposing litters. Since previous work has suggested that litter VOCs may be capable of influencing bacterial communities and nitrogen dynamics in soil, we also characterized soil bacterial communities, total microbial biomass, and nutrient concentrations at the end of the 72-day incubation to determine if exposure to litter VOCs had influenced these soil characteristics.

\section{Methods}

Soil and litter collection

One soil and two litter types were collected from the Calhoun Experimental Forest in South Carolina, USA (Lauber et al. 2008; Richter and Markewitz 2001). Mineral soil was collected from the top $5 \mathrm{~cm}$ of the profile in a monoculture loblolly pine stand (Pinus 
taeda). The soil is a loamy sand with a $\mathrm{pH}$ of 3.6 and an organic carbon concentration of $9 \mathrm{~g} \mathrm{C} \mathrm{kg}^{-1}$. Additional details on soil edaphic factors can be found in Lauber et al. (2008). After collection, soil was sieved to $2 \mathrm{~mm}$, homogenized, and shipped to the University of Colorado where it was stored at $4^{\circ} \mathrm{C}$. Pine litter was collected from the same loblolly pine stand and red maple (Acer rubrum) litter was collected from a nearby forest. The pine and maple litters were dried at $75^{\circ} \mathrm{C}$ within 1 week of collection.

\section{Microcosm design}

Equal volumes of soil and litter were weighed out into individual polystyrene Petri dishes $(15 \mathrm{~cm}$ in diameter) with $50 \mathrm{~g}$ soil (dry weight) or $3 \mathrm{~g}$ litter (dry weight) per dish, and adjusted to $50 \%$ of water holding capacity (WHC). Petri dishes were placed into 1.891 jars with Teflon-lined lids and were then connected to an air-flow-through system fitted with Teflon tubing and air tight Swagelok fittings (diagrammed in Fig. 1). This system pumped atmospheric air through an activated charcoal filter to remove background VOCs and then through each jar

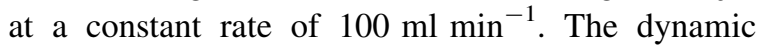
flow-through system was designed to prevent

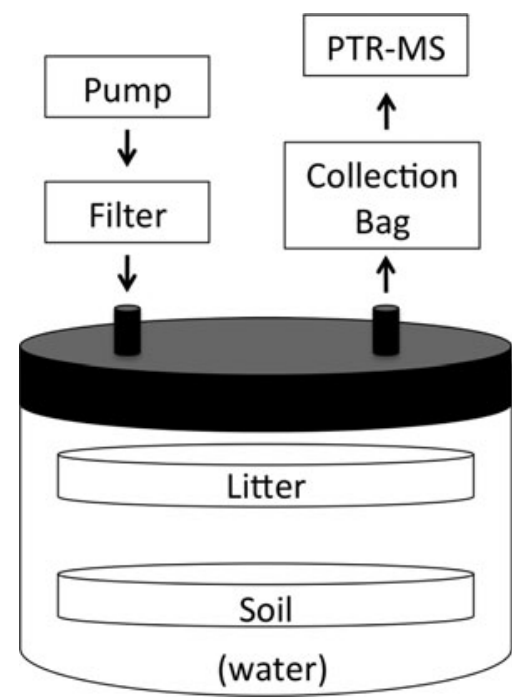

Fig. 1 Schematic of flow-through system. Note that the litter and soil samples do not come in direct contact, they are only sharing the same headspace. Note also that some of the microcosms contain only soil or only litter. The water is included in the bottom of each microcosm to keep the soil and/ or litter at a constant moisture level unnatural build up of $\mathrm{VOC}$ and $\mathrm{CO}_{2}$ concentrations in each jar (accumulation beyond what we might expect to observe in the field) but still allowing for circulation of VOCs within each jar. Each jar contained one of the following five treatments: soil alone, pine litter alone, maple litter alone, pine litter plus soil, and maple litter plus soil. Jars containing both soil and litter shared the jar headspace and were not in direct contact. To maintain samples at $50 \%$ of WHC throughout the incubation period, $50 \mathrm{ml}$ of water was added to the bottom of each jar and individual samples were weighed on a weekly basis with water added if necessary, after gas sampling. Jars containing only Petri plates and water were used as controls to measure background VOC concentrations in the air pumped through the system. There were four replicates of each of the five treatments and control (Petri plates and water), for a total of 24 jars. Jars were equilibrated for 6 days prior to the first sampling. The entire apparatus was stored at $21^{\circ} \mathrm{C}$ throughout the 72-day incubation period.

VOC and $\mathrm{CO}_{2}$ flux measurements

At 12 time points during the 72-day incubation period, VOC fluxes were measured by connecting the outlet of each jar to a 101 Tedlar gas collection bag (SKC Inc., Eighty-Four, PA USA) for approximately $1 \mathrm{~h}$, collecting approximately 61 of air per jar. Each bag was cleaned with successive flushes of $\mathrm{N}_{2}$ gas before collection. Bags were then connected directly to a proton transfer reaction-mass spectrometer (PTR-MS; Ionicon $\mathrm{GmbH}$, Innsbruck, Austria) (Lindinger et al. 1998). Operating at 125 Townsends (Td) $(1 \mathrm{Td}=$ $10^{-17} \mathrm{~V} \mathrm{~cm}^{2}$ molecule ${ }^{-1}$ ) to reduce VOC fragmentation, and on the "scan mode", the instrument performed mass scans (20-180 amu) every $0.2 \mathrm{~s}$. Ionization of $\mathrm{O}_{2}^{+}$was negligible as the $\mathrm{O}_{2}{ }^{+}: \mathrm{H}_{3} \mathrm{O}^{+}$ ratio is $\leq 3.5 \%$. Three mass scans were performed for each sample and averaged across treatments.

To calculate the molecular density of each VOC, [R], the following equation (Eq. 1) was used, accounting for drift tube temperature $(333 \mathrm{~K})$ and drift tube pressure (2.19) (Zhao and Zhang 2004; de Gouw et al. 2003).

$\left[\mathrm{RH}^{+}\right]=\mathrm{k}_{1}\left[\mathrm{H}_{3} \mathrm{O}^{+}\right][\mathrm{R}] \mathrm{t}+\mathrm{k}_{2}\left[\mathrm{H}_{3} \mathrm{O}^{+}\left(\mathrm{H}_{2} \mathrm{O}\right)\right][\mathrm{R}] \mathrm{t}$

Where $\left[\mathrm{H}_{3} \mathrm{O}^{+}\right],\left[\mathrm{H}_{3} \mathrm{O}^{+}\left(\mathrm{H}_{2} \mathrm{O}\right)\right]$ and $\left[\mathrm{RH}^{+}\right]$are ion signals (cps) at mass $21(\times 500)$, mass $39(\times 250)$, and 
the target VOC, and where the average time (t) spent by reactants in drift tube $(105 \mathrm{~ms})$ and rate coefficients $\left(\mathrm{k}_{1}\right.$ and $\left.\mathrm{k}_{2}\right)$ between target VOC and $\mathrm{H}_{3} \mathrm{O}^{+}$or $\mathrm{H}_{3} \mathrm{O}^{+}\left(\mathrm{H}_{2} \mathrm{O}\right)$. Including $\mathrm{H}_{3} \mathrm{O}^{+}\left(\mathrm{H}_{2} \mathrm{O}\right)$ into the reaction is a modification by Lindinger et al. (1998). As all VOCs are identified by their mass alone, the compound identifications have not been confirmed. For this study we chose to detect a range of masses, rather than focus on selected compounds, in order to gain a more comprehensive perspective on the types and quantities of VOCs emitted from the samples. Emission rates were calculated per jar by considering the flow rate $\left(100 \mathrm{ml} \mathrm{min}^{-1}\right)$ through each jar and the standard volume of air $\left(32.991 \mathrm{~mol}^{-1}\right)$. Standard volume was corrected for the altitude of Boulder, CO, USA.

Soil $\mathrm{CO}_{2}$ production was measured after each collection for the VOC analyses. Using a static incubation procedure, airflow through the jars was stopped and all 24 jars were sealed using gas-tight caps with silicone septa for 24-72 h. After the allotted time, $3 \mathrm{ml}$ of headspace air was collected with a gas-tight syringe and $\mathrm{CO}_{2}$ concentrations were analyzed using an infrared gas analyzer (IRGA) (CA10a, Sable Systems, Inc., Las Vegas, NV, USA). $\mathrm{CO}_{2}$ concentrations inside the jars were never allowed to exceed $2 \%$. Net $\mathrm{CO}_{2}$ production was calculated by measuring the increase in headspace $\mathrm{CO}_{2}$ concentrations relative to the control jars over time $(\mu \mathrm{g} \mathrm{C}-$ $\mathrm{CO}_{2} \mathrm{~h}^{-1}$ sample $^{-1}$ ).

Soil and microbial community analyses

To determine how exposure to litter VOCs influenced process rates and bacterial community composition within the soil, we measured the following soil characteristics at the end of the 72-day incubation period: microbial biomass, extractable nitrogen, and bacterial community composition. Microbial biomass was measured for each soil treatment (soil, soil plus pine, soil plus maple) using the substrate-induced respiration (SIR) procedure as described in Fierer et al. (2003). Briefly, we placed $5 \mathrm{~g}$ of soil in a $50 \mathrm{ml}$ glass vial fitted with a rubber septa and added $10 \mathrm{ml}$ of a $1.2 \% \mathrm{w} / \mathrm{v}$ yeast extract solution. The tubes were shaken continuously and headspace $\mathrm{CO}_{2}$ concentrations were measured after $15 \mathrm{~min}, 2 \mathrm{~h}$, and $4 \mathrm{~h}$ using the procedure described above. The potential SIRresponsive microbial biomass pool is represented by the average respiration rate $\left(\mu \mathrm{g} \mathrm{C}-\mathrm{CO}_{2} \mathrm{~g} \mathrm{soil}^{-1} \mathrm{~h}^{-1}\right)$ over the $4 \mathrm{~h}$ period. Total extractable ammonium $\mathrm{N}$ and nitrate + nitrite $\mathrm{N}$ was determined in the Kiowa Chemistry Laboratory at the Institute of Arctic and Alpine Research (INSTAAR) using an OI Analytical Flow Solution IV Analyzer with detection levels of $0.13 \mathrm{uEQ} / 1$ and $0.04 \mathrm{uEQ} / \mathrm{l}$.

To determine bacterial community composition, each soil sample was homogenized and DNA was extracted using the MoBio PowerSoil DNA extraction kit from approximately $0.25 \mathrm{~g}$ of soil, following the manufactures protocol with a few minor modifications: placing extraction tubes in a $65^{\circ} \mathrm{C}$ water bath and reducing the bead beating time from $10 \mathrm{~min}$ to 2 min. PCR amplification, sample pooling and pyrosequencing were carried out following protocol described previously (Lauber et al. 2009). Briefly, the 27-338 region (E. coli numbering) the 16S rRNA gene was amplified for each sample using error correcting barcoded primers described in Hamady et al. (2008). The $27 \mathrm{~F}$ forward primer contained the Roche 454 ' $A$ ' pyrosequencing adapter while the reverse 338 primer contained a 12-bp barcode, a 'TC' linker and the Roche 454 ' $\mathrm{B}$ ' sequencing adapter. PCR reactions contained forward and reverse primers $(30 \mu \mathrm{M})$, template DNA $(1.5 \mu \mathrm{l})$, and Platinum ${ }^{\circledR}$ PCR SuperMix (Invitrogen, Carlsbad, CA, USA) $(22.5 \mu \mathrm{l})$. Samples were amplified in triplicate, pooled and cleaned using the MoBio 96 htp CR clean up kit. The cleaned amplicons were then quantified using Quant-IT Picogreen dsDNA Reagent (Invitrogen) and a single tube containing equal amounts of PCR amplicons from each sample was sent to the Environmental Genomics Core Facility at the University of South Carolina to be run on a Roche FLX 454 pyrosequencing machine (Lauber et al. 2009). Sequences were classified against the Greengenes database (DeSantis et al. 2006) and phylogenetic analyses were completed following the procedures described previously (Fierer et al. 2008).

\section{Statistical analyses}

To compare VOC types and concentrations, $\mathrm{CO}_{2}$ levels, biomass and extractable $\mathrm{N}$ between treatments, the program $\mathrm{R}$ version 2.8.1 (The R Foundation for Statistical Computing) was used. VOCs and $\mathrm{CO}_{2}$ emissions, biomass, and extractable $\mathrm{N}$ were compared between treatments using a one-way analysis of 
variance (ANOVA). The proportional emission rates of the 10 most abundant VOC compounds emitted by each treatment were further analyzed using principal component analyses (PCA) to visualize overall differences in the types of VOCs emitted from each treatment and an analysis of similarity (ANOSIM) to determine whether the types of VOCs emitted are distinct across treatment. We tested for significant differences in bacterial communities from the three soil treatments (soil alone, maple litter plus soil, pine litter plus soil) using the unweighted and weighted Unifrac algorithms (Lozupone et al. 2006; Lozupone and Knight 2008; Lozupone and Knight 2005). Pairwise unweighted and weighted Unifrac distance matrices were analyzed using ANOSIM to determine differences between individual treatments.

\section{Results}

VOC and $\mathrm{CO}_{2}$ flux measurements

Over 100 VOCs with unique masses were identified from the samples during the 72-day incubation period. Across the five treatments, 10 compounds accounted for $90-96 \%$ of all emitted VOCs (Table 1). Of those 10 compounds, two compounds, mass 33 (methanol) and mass 137 plus mass 81 (monoterpene and its breakdown product) were the most dominant. Methanol accounted for $\sim 90 \%$ of emissions from maple litter treatments and $\sim 30 \%$ of emissions from pine litter treatments. Monoterpenes accounted for another $\sim 35 \%$ of VOC emissions from the pine litter treatments. Further, each treatment had a unique VOC signature as evident from the principal components analysis of the proportional representation of the top 10 compounds from each sample (Fig. 2) and the ANOSIM analyses (Global $\mathrm{R}=0.92, p<0.001)$. VOCs from the soil alone treatment were different from those emitted from either litter type (Table 1, Fig. 2) with individual VOCs emitted in far lower amounts from soil (some VOCs were even consumed by soil from the background air). Litter plus soil treatments emitted similar percentages of methanol and monoterpenes to their litter alone counterpart, however, these treatments had distinct VOC signatures due to differences in the percentages of other major VOCs (Table 1, Fig. 2).

To further analyze the differences in VOC emissions across the five treatments, we calculated total VOC, methanol, acetone and monoterpene emissions for each treatment over the entire incubation period (Fig. 3). Rates of VOC emissions varied across the litter, litter plus soil and soil treatments. Both litter treatments emitted approximately an order of magnitude more VOCs than soil, and litter plus soil emitted significantly $(p<0.001$ for both litter types) less VOCs than treatments of litter alone (Fig. 3a). For example, soil VOC emissions ranged between a net consumption of $-42 \mu \mathrm{g}-\mathrm{C}-\mathrm{VOC}$ to a net production

Table 1 Top 10 emitted compounds percent emitted by each treatment type as determined by PTR-MS, averaged over the 72-day period

\begin{tabular}{|c|c|c|c|c|}
\hline Protonated mass (compound) & Maple & Maple + soil & Pine & Pine + soil \\
\hline M33 (methanol) & $89.4 \% \pm 0.01$ & $90.3 \% \pm 0.00$ & $31.5 \% \pm 0.37$ & $28.8 \% \pm 0.02$ \\
\hline M137 (monoterpene) & $0.16 \% \pm 0.00$ & $0.49 \% \pm 0.00$ & $22.4 \% \pm 0.02$ & $20.6 \% \pm 0.01$ \\
\hline M59 (acetone) & $4.73 \% \pm 0.01$ & $3.60 \% \pm 0.00$ & $13.4 \% \pm 0.01$ & $16.4 \% \pm 0.01$ \\
\hline M81 (monoterpene) & $0.03 \% \pm 0.00$ & $0.30 \% \pm 0.00$ & $12.5 \% \pm 0.01$ & $11.1 \% \pm 0.01$ \\
\hline M153 (vanillin) & $0.54 \% \pm 0.00$ & $1.08 \% \pm 0.00$ & $7.16 \% \pm 0.01$ & $10.0 \% \pm 0.01$ \\
\hline M51 (unknown) & $1.82 \% \pm 0.00$ & $1.49 \% \pm 0.00$ & $0.75 \% \pm 0.00$ & $0.73 \% \pm 0.00$ \\
\hline M138 (ethyl3-methylbutanoate) & $0.00 \% \pm 0.00$ & $0.053 \% \pm 0.00$ & $2.47 \% \pm 0.00$ & $2.13 \% \pm 0.00$ \\
\hline M55 (2-butin) & $0.65 \% \pm 0.01$ & $0.24 \% \pm 0.00$ & $0.11 \% \pm 0.00$ & $2.87 \% \pm 0.03$ \\
\hline M93 (toluene) & $0.23 \% \pm 0.00$ & $0.05 \% \pm 0.00$ & $1.04 \% \pm 0.00$ & $0.87 \% \pm 0.00$ \\
\hline M135 (unknown) & $0.04 \% \pm 0.00$ & $0.01 \% \pm 0.00$ & $1.16 \% \pm 0.00$ & $0.95 \% \pm 0.00$ \\
\hline
\end{tabular}

These 10 compounds made up 97.6, 92.5, 97.6, and 94.4\% of all VOC emissions during the study across the four treatments containing litter. The soil alone samples had very low emission rates of these 10 VOCs and thus percentages are not shown here Standard error, in percentages, shown following \pm 


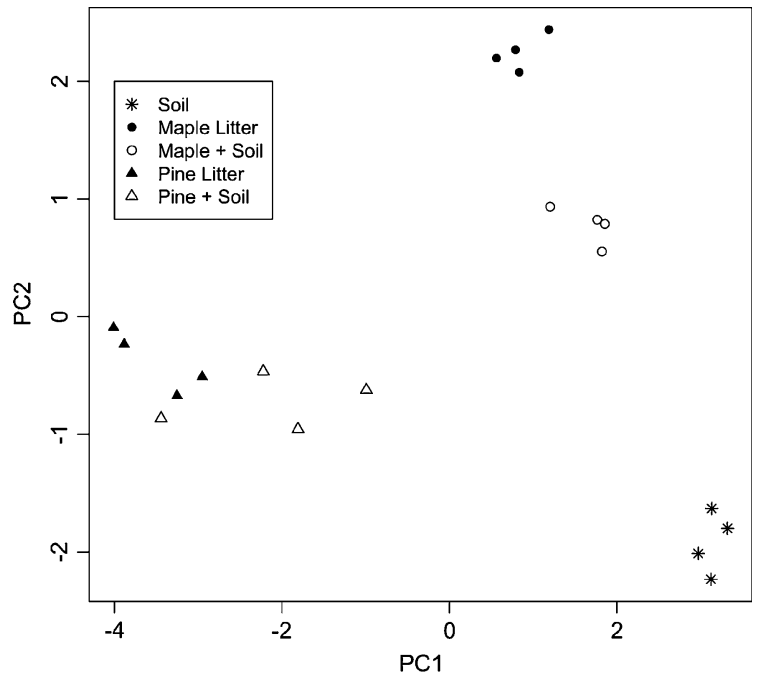

Fig. 2 Principal components analysis (PCA) showing differences in VOC profiles across the five treatments. The analyses are based on the percentages of the 10 most abundant VOCs emitted over the 72 day period (shown in Table 1) and therefore the patterns shown here are not influenced by changes in the total rate of VOC emissions across the treatment. PC1 represents $60.0 \%$ of the observed variation and PC2 represent $19.4 \%$ of observed variation

of $32 \mu \mathrm{g}-\mathrm{C}-\mathrm{VOC}$. Conversely, maple litter emissions ranged from 2668 to $4274 \mu \mathrm{g}-\mathrm{C}-\mathrm{VOC}$, five times more than maple plus soil (489 to $716 \mu \mathrm{g}-\mathrm{C}-\mathrm{VOC}$ ); and pine emissions ranged from 1003 to $1737 \mu \mathrm{g}-\mathrm{C}-$ VOC, three times more than pine plus soil (260 to
$554 \mu \mathrm{g}-\mathrm{C}-\mathrm{VOC}$ ) (Fig. 3a). VOC emission rates dropped over time in all treatments, with differences between treatment types observed until approximately day 30 (Fig. 4). After this time, the difference in emission rates between the litter alone and litter plus soil treatments were negligible.

Throughout the 72-day period, the amount of carbon emitted as $\mathrm{CO}_{2}$ was consistently and significantly higher than carbon emitted in the form of VOCs (Fig. 5). While $\mathrm{CO}_{2}$ production ranged from $12,854 \mu \mathrm{g}-\mathrm{C}$ sample $^{-1}$ (soil) to $151,429 \mu \mathrm{g}-\mathrm{C}$ sam$\mathrm{ple}^{-1}$ (maple plus soil), VOC production ranged from $-28.27 \mu \mathrm{g}-\mathrm{C}$ sample $^{-1}$ (soil alone, where there was net consumption of VOCs from background air) to $2892.44 \mu \mathrm{g}-\mathrm{C}$ sample ${ }^{-1}$ (maple litter). Additionally, treatments of litter plus soil produced more $\mathrm{CO}_{2}$ than their litter alone counterparts (Fig. 5), but these differences were only significant between the pine and pine plus soil treatments (Fig. 5).

Soil and microbial community analyses

Overall, exposure to litter VOCs had no significant influence on the measured soil nutrient pools or soil microbial community composition. Between the three soil treatments there was no significant difference $(p=0.08)$ in extractable ammonium concentrations between the three treatments, with values ranging
Fig. 3 VOC emissions for each treatment type. a Total VOCs, b methanol (M33), c acetone (M59) and d monoterpenes (M137 + M81). Error bars indicate \pm standard error of the mean $(n=4)$.

Significant differences between the pair of litter alone versus litter and soil together ( $t$-test) are designated with one asterisk $(p<0.001)$
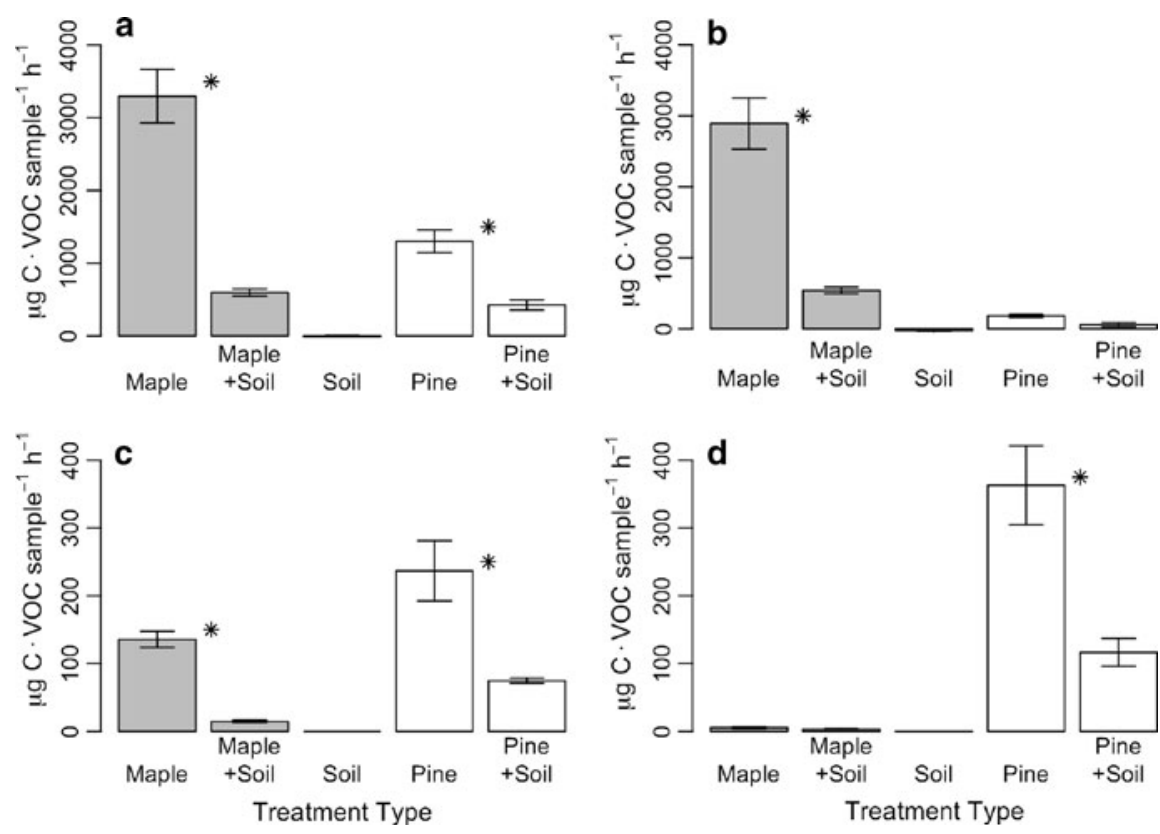
Fig. 4 Average VOC and $\mathrm{CO}_{2}$ emission rates at each sampling day for each of the five treatment types a VOC production for maple treatments. b VOC production for pine treatments. $\mathbf{c} \mathrm{CO}_{2}$ production for maple treatments. $\mathbf{d ~} \mathrm{CO}_{2}$ production for pine treatments. Error bars indicate \pm standard error of the mean $(n=4)$
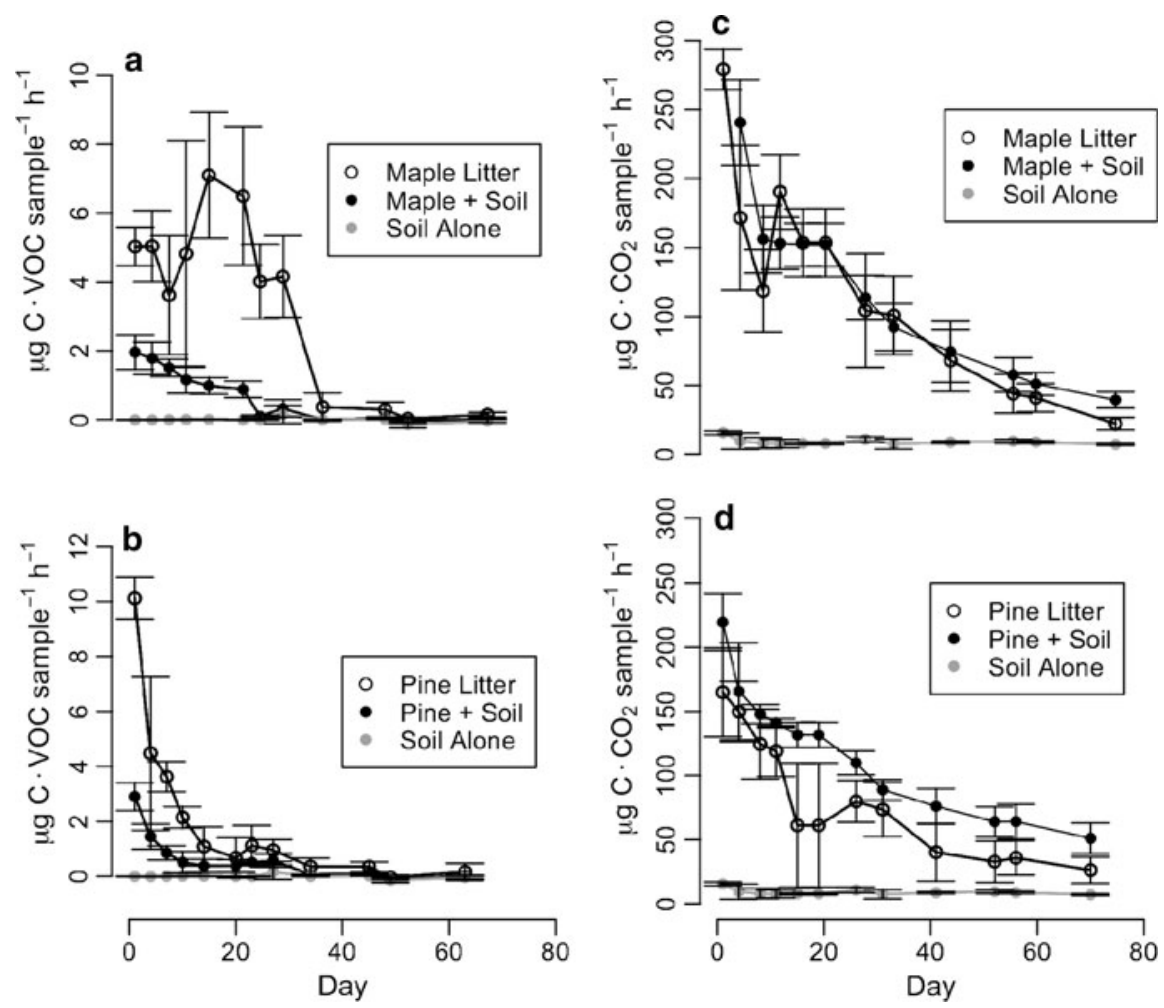

from 4.78 to $8.93 \mathrm{mg} \mathrm{N}^{-1}$, and no significant difference $(p=0.52)$ in extractable nitrate concentrations with values ranging from 0.01 to $0.82 \mathrm{mg} \mathrm{N}^{-1}$. Likewise, there was no significant difference $(p=0.38)$ in microbial biomass levels, with all treatments falling within the range of 4.54$6.18 \mu \mathrm{g} \mathrm{C}-\mathrm{CO}_{2} \mathrm{~g} \mathrm{soil}^{-1} \mathrm{~h}^{-1}$.

Of the 12 soil samples sequenced, an average of 2,100 sequences (range: 1236 to 4953) were obtained for each individual sample. The bacterial communities were dominated by members of the Acidobacteria, Proteobacteria, Bacteroidetes, and Actinobacteria phyla, which represented $49.5,26.4,7.7$, and $6.1 \%$ of sequences, respectively (Fig. 6a). Overall, community composition in the soils receiving maple or pine litter VOCs were similar to those in the control treatments with no evidence for consistent shifts in community composition (Fig. 6b). This is confirmed by the ANOSIM analysis of the unweighted and weighted UniFrac pairwise distances; there was no significant difference between the three treatment types, (ANOSIM of unweighted Unifrac Global $\mathrm{R}=0.05, p=0.3$; ANOSIM of weighted Unifrac: Global $\mathrm{R}=0.02$, $p=0.4)$.

\section{Discussion}

Differences in VOC emissions across treatments

Although more than 100 different VOC masses were measured during this 72-day experiment, methanol was the dominant VOC emitted across the treatments, accounting for 30-90\% of total VOC emissions. Other studies have also found methanol to be one of the dominant compounds emitted from litter and soil (Schink and Zeikus 1980; Stahl and Parkin 1996; Asensio et al. 2007). A number of studies using gas chromatography mass spectrometry (GCMS) analyses to characterize soil or litter VOC emissions have not detected methanol (Leff and Fierer 2008), but this is likely due to the inability of most GC-MS analyses to detect compounds with relatively low molecular weights (such as methanol) that are readily detected with the PTR-MS analyses used here. While some methanol may be produced via abiotic processes (Warneke et al. 1999), the microbial breakdown of plant pectin is likely to be the dominant source of methanol in litter and soil (Schink and Zeikus 1980). Though this previous 
Fig. 5 Total $\mathrm{VOC}$ and $\mathrm{CO}_{2}$ emissions for each treatment type. a Total VOC Production for maple treatments. b Total $\mathrm{CO}_{2}$ production for maple treatments. c Total VOC production for pine treatments. d Total $\mathrm{CO}_{2}$ production for pine treatments. Error bars indicate \pm standard error of the mean $(n=4)$. Hatched lines represent the amount of $\mathrm{CO}_{2}$ that should be observed if soil and litter emissions were additive. Significant differences between litter alone versus litter plus soil treatments $(p<0.05)$ are designated with asterisks

Fig. 6 a Pie chart representing the average percent abundance of the most abundant phyla found in the soil alone. b In soils from maple plus soil and pine plus soil treatments, the percent change from soil alone was not significant for any of the phyla (ANOVA)
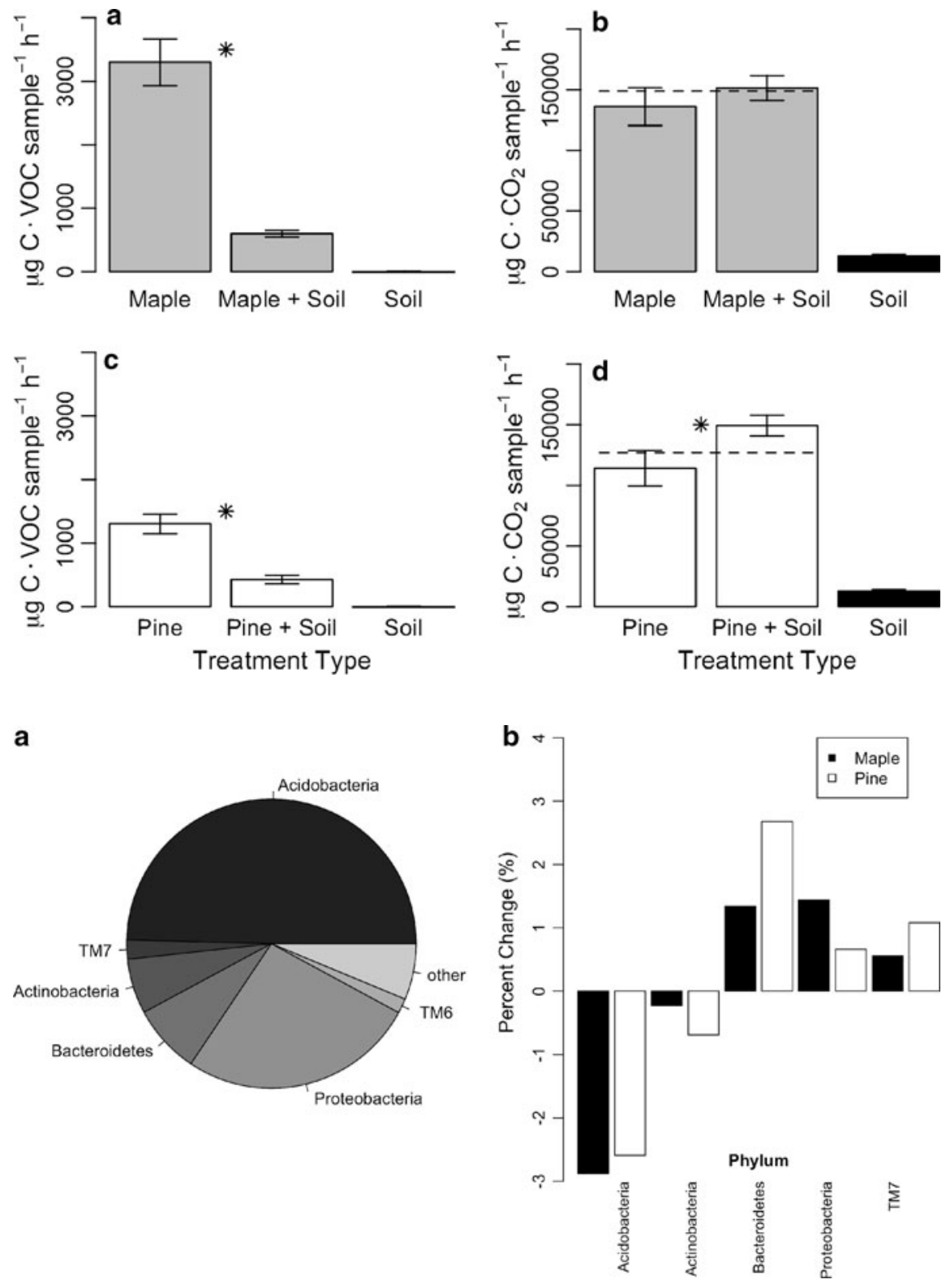

work and the close correspondence between $\mathrm{CO}_{2}$ and VOC emission rates over time (Fig. 4) suggests that the majority of methanol is produced biotically by microbes, it is important to note that this study was not designed to distinguish between abiotic and biotic sources of VOCs.

After methanol, the other dominant VOCs emitted were monoterpenes and acetone, which previous studies have also shown to be commonly emitted from soils and litters (Asensio et al. 2007; Jacob et al. 2002; Isidorov and Jdanova 2002; Leff and Fierer
2008). Pine litter emitted higher levels of monoterpenes than maple litter, a pattern we would expect given that monoterpenes are produced by all conifers and are stored in the needles where they readily volatize from needle tissue (Litvak et al. 2008). Likewise, other studies have also documented significant acetone emissions from soil and litter in the lab and field (Schade and Goldstein 2001) and it has been hypothesized that the majority of this acetone production results from abiotic processes (Warneke et al. 1999). 
VOC production was monitored and then summed over the 72-day experiment to identify differences between treatment types (Fig. 3 and 4). On a per gram basis, net VOC emissions were $90 \%$ lower from soil than from the litter samples, confirming the results of Leff and Fierer (2008) who noted a similar difference between litter and mineral soil VOC emissions. Further, the litter plus soil treatments emitted 2-5 times less total VOCs than litter alone suggesting that soil is capable of acting as a sink for VOCs produced during litter decomposition. This has been documented previously by Asensio et al. (2007), with concentration, temperature, and moisture controlling the specific rates of VOC consumption by soil (Asensio et al. 2007). Although we cannot determine the precise mechanisms responsible for this observation, there are a number of lines of evidence suggesting that the lower VOC emission rates in the litter plus soil treatments is a result of consumption of VOCs by soil microorganisms. First, both Cleveland and Yavitt (1998) and Owen et al. (2007) have demonstrated that consumption of specific VOCs in field soils result from microbial activities, not abiotic processes, such as sorption. Similarly, the growth of bacterial isolates in culture has been shown to be promoted by VOCs (Vespermann et al. 2007; Mackie and Wheatley 1999) and the addition of VOCs to bulk soil directly increased $\mathrm{CO}_{2}$ production (Amaral and Knowles 1997; Paavolainen et al. 1998; Smolander et al. 2006).

In this study, we also found evidence that soil microorganisms were capable of catabolizing VOCs. In the litter plus soil treatments we observed higher $\mathrm{CO}_{2}$ concentrations than expected, (i.e. if respiration from litter and soil treatments was simply additive) (Fig. $5 b$ and d). The amount of additional carbon released by litter plus soil treatments, was similar in quantity to the carbon produced as VOCs from the litter alone treatments, indicating that soil microbes may have utilized VOCs as a carbon source (Fig. 5a and c). Together these results suggest that VOC consumption, or more specifically, the transfer of VOCs from litter to soil, may represent an important aspect of soil carbon dynamics. However, it remains to be determined to what extent such VOC flux may impact soil carbon dynamics in the field. Although litter VOCs only increased $\mathrm{CO}_{2}$ production by 2.5$15 \%$ in this study, and the increase was only significant in the pine plus soil treatment, we may be underestimating VOC consumption rates given that headspace VOC concentrations were kept very low in our constant flow-through system and (arguably) lower than at the litter/mineral soil interface in many soil profiles. Likewise, the transfer of VOCs from litter to soil may be particularly important in periods of low soil moisture when transfer of soluble organic carbon would be limited (Neff and Asner 2001).

Effects of VOCs on soil microbial communities and nutrient cycling

Exposure to litter VOCs caused minimal changes in soil microbial biomass levels, extractable $\mathrm{N}$ concentrations, and soil bacterial community composition. In all likelihood, we did not observe significant effects of VOCs on these soil characteristics because litter VOCs did not represent a large source of organic C inputs to soil. The amount of carbon emitted from litter as VOCs was 5-50 times lower than the amount of carbon emitted from the soil as $\mathrm{CO}_{2}$ (Fig. 4). Smolander et al. (2006) observed changes in microbial biomass when adding different terpene compounds, yet the soils were exposed to concentrations of VOCs (up to $667 \mathrm{mg} \mathrm{m}^{-3}$ ) that were much higher than concentrations detected in this study (up to $1 \mathrm{mg} \mathrm{m}^{-3}$ ). Our study also did not observe shifts in soil nitrogen dynamics in contrast to previous studies that have found VOCs to influence soil nitrogen dynamics (inhibiting nitrification and $\mathrm{N}$ mineralization rates) (Smolander et al. 2006; Paavolainen et al. 1998; White 1988). Either the high concentrations used in these previous studies overestimated the influence of VOCs on soil N dynamics, or our experimental setup (which did not allow for the build-up of high VOC concentrations) resulted in an underestimation of the actual impact that VOCs may have on soil $\mathrm{N}$ cycling.

While both bacteria and fungi are capable of producing and consuming VOCs (Vespermann et al. 2007; Wheatley et al. 1997; Mackie and Wheatley 1999), we chose to focus our study on the response of the bacterial communities, as bacteria are particularly adept at consuming a range of VOCs (Bunge et al. 2008; Mayrhofer et al. 2006). Although previous work has shown that VOCs are capable of inhibiting and stimulating specific microbial taxa (Stotzky and Schenck 1976; Wheatley 2002; Mackie and Wheatley 
1999; Tsuji et al. 1990), the presence of litter VOCs to soils did not lead to appreciable changes in the relative abundances of individual bacterial taxa or overall bacterial community composition. We expected to observe soils exposed to litter VOCs to have increased in the relative abundances of specific groups, such as the methylotrophs, which can consume methanol (Tsuji et al. 1990), yet such changes were not detected in this study. Although we observed high consumption rates of methanol, monoterpenes, acetone, and other compounds, it is likely that most compounds can either be easily consumed by a wide range of bacteria or were not at sufficiently high concentrations to induce detectable changes in the soil bacterial communities over the course of the incubation period. Although other microbial taxa not characterized here (including fungi and archaea) may have exhibited more dramatic responses to the litter VOC additions, this work does demonstrate that soil bacteria exhibit minimal shifts in community structure after a 72-day exposure to (relatively) low concentrations of VOCs from decomposing litter.

\section{Conclusion}

Litter produces a range of VOCs and the types of VOCs emitted are strongly dependent on the type of litter being decomposed. Many of these VOCs appear to be metabolized in soil with soil representing a net sink of litter VOCs and, even at low concentrations, litter VOCs can represent an important carbon source to soil, elevating microbial activity. Although we did not demonstrate any significant effects of litter VOC additions on soil microbial biomass, nitrogen dynamics or community composition, such affects may be more evident in settings where soils are supplemented with VOCs at higher concentrations or for longer periods of time. Future work addressing the influence of VOCs on soil processes and soil biota in the field will improve our understanding of this understudied mechanism of litter-soil interaction.

Acknowledgements We would like to thank members of the Fierer lab for their valuable comments on previous drafts of this manuscript. We would also like to thank Mark Bradford and Mike Strickland for their help with sample collection, Rob Knight and Micah Hamady for their help with the sequence analyses, Michael Wilkinson for his guidance and aide in sampling, and Russ Monson for making the PTR-MS available for our use. Finally, we thank the three anonymous reviewers for their thoughtful comments. This work was funded by grants awarded to N.F. from the National Science Foundation and the Andrew W. Mellon Foundation.

\section{References}

Amaral JA, Knowles R (1997) Inhibition of methane consumption in forest soils and pure cultures of methanotrophs by aqueous forest soil extracts. Soil Biol Biochem 29:1713-1720

Amaral JA, Knowles R (1998) Inhibition of methane consumption in forest soils by monoterpenes. J Chem Ecol 24:723-734

Asensio D, Penuelas J, Filella I, Llusia J (2007) On-line screening of soil VOCs exchange responses to moisture, temperature and root presence. Plant Soil 291:249-261

Bunge M, Araghipour N, Mikoviny T, Dunkl J, Schnitzhofer R, Hansel A, Schinner F, Wisthaler A, Margesin R, Mark TD (2008) On-line monitoring of microbial volatile metabolites by proton transfer reaction-mass spectrometry. Appl Environ Microbiol 74:2179-2186

Cleveland CC, Yavitt JB (1998) Microbial consumption of atmospheric isoprene in a temperate forest soil. Appl Environ Microbiol 64:172-177

de Gouw J, Warneke C, Karl T, Eerdekens G, van der Veen C, Fall R (2003) Sensitivity and specificity of atmospheric trace gas detection by proton-transfer-reaction mass spectrometry. Int J Mass Spectrom 223:365-382

DeSantis TZ, Hugenholtz P, Larsen N, Rojas M, Brodie EL, Keller K, Huber T, Dalevi D, Hu P, Andersen GL (2006) Greengenes, a chimera-checked 16S rRNA gene database and workbench compatible with ARB. Appl Environ Microbiol 72:5069-5072

Fierer N, Schimel JP, Holden PA (2003) Variations in microbial community composition through two soil depth profiles. Soil Biol Biochem 35:167-176

Fierer N, Hamady M, Lauber CL, Knight R (2008) The influence of sex, handedness, and washing on the diversity of hand surface bacteria. Proc Natl Acad Sci 105:1799417999

Hamady M, Walker JJ, Harris JK, Gold NJ, Knight R (2008) Error-correcting barcoded primers for pyrosequencing hundreds of samples in multiplex. Nat Methods 5:235237. doi:10.1038/nmeth. 1184

Isidorov V, Jdanova M (2002) Volatile organic compounds from leaves litter. Chemosphere 48:975-979. doi: PIIS0045-6535(02)00074-7

Jacob DJ, Field BD, Jin EM, Bey I, Li Q, Logan JA, Yantosca RM, Singh HB (2002) Atmospheric budget of acetone. J Geophys Res 107(D10):4100

Kesselmeier J, Staudt M (1999) Biogenic volatile organic compounds (VOC): an overview on emission, physiology and ecology. J Atmos Chem 33:23-88

Lauber CL, Strickland MS, Bradford MA, Fierer N (2008) The influence of soil properties on the structure of bacterial and fungal communities across land-use types. Soil Biol Biochem 40:2407-2415. doi:10.1016/j.soilbio.2008.05.021 
Lauber CL, Hamady M, Knight R, Fierer F (2009) Pyrosequencing-based assessment of soil $\mathrm{pH}$ as a predictor of soil bacterial community structure at the continental scale. Appl Environ Microbiol 75:5111-5120. doi:10.1128/AEM.003 35-09

Leff JW, Fierer N (2008) Volatile organic compound (VOC) emissions from soil and litter samples. Soil Biol Biochem 40:1629-1636. doi:10.1016/j.soilbio.2008.01.018

Lindinger W, Hansel A, Jordan A (1998) On-line monitoring of volatile organic compounds at pptv levels by means of proton-transfer-reaction mass spectrometry (PTR-MS) medical applications, food control and environmental research. Int J Mass Spectrom Ion Process 173:191-241. doi:10.1016/S0168-1176(97)00281-4

Litvak ME, Madronich S, Monson RK (2008) Herbivoreinduced monoterpene emissions from coniferous forests: Potential impact on local tropospheric chemistry. Ecol Appl 9:1147-1159

Lozupone CA, Knight R (2005) UniFrac: a new phylogenetic method for comparing microbial communities. Appl Environ Microbiol 71:8228-8235. doi:10.1128/AEM.71. 12.8228-8235.2005

Lozupone CA, Knight R (2008) Species divergence and the measurement of microbial diversity. FEMS Microbiol Rev 32:557-578. doi:10.1111/j.1574-6976.2008.00111

Lozupone CA, Hamady M, Knight R (2006) UniFrac: an online tool for comparing microbial community diversity in a phylogenetic context. Bioinformatics 7:371. doi:10.1186/ 1471-2105-7-371

Mackie AE, Wheatley RE (1999) Effects and incidence of volatile organic compound interactions between soil bacterial and fungal isolates. Soil Biol Biochem 31:375385

Mayrhofer S, Mikoviny T, Waldhuber S, Wagner AO, Innerebner G, Frank-Whittle IH, Mark TD, Hansel A, Insam H (2006) Microbial community related to volatile organic compound (VOC) mission in household biowaste. Environ Microbiol 8:1960-1974. doi:10.1111/j.1462-2920. 2006.01076

Monson RK (2002) Volatile organic compound emissions from terrestrial ecosystems: A primary biological control over atmospheric chemistry. Isr J Chem 42:29-42

Monson RK, Holland EA (2003) Biospheric trace gas fluxes and their control over tropospheric chemistry. Annu Rev Ecol Syst 32:547-576

Neff JC, Asner GP (2001) Dissolved organic carbon in terrestrial ecosystems: synthesis and a model. Ecosystems 4:29-48. doi:10.1007/s100210000058

Owen SM, Clark S, Pompe M, Semple KT (2007) Biogenic volatile organic compounds as potential carbon sources for microbial communities in soil from the rhizosphere of Populus tremula. FEMS Microbiol Lett 268:34-39. doi: 10.1111/j.1574-6968.2006.00602

Paavolainen L, Kitunen V, Smolander A (1998) Inhibition of nitrification in forest soil by monoterpenes. Plant Soil 205:147-154
Richter D, Markewitz D (2001) Understanding soil change. Cambridge University Press, Cambridge, UK

Schade GW, Crutzen PJ (1999) CO emissions from degrading plant matter (II): estimate of a global source strength. Tellus B 51:909-918. doi:10.1034/j.1600-0889.1999.t014-00004

Schade GW, Goldstein AH (2001) Fluxes of oxygenated volatile organic compounds from a ponderosa pine plantation. J Geophys Res 106:3111-3123

Schink B, Zeikus J (1980) Microbial methanol formation: a major end product of pectin metabolism. Curr Microbiol 4:387-389. doi:10.1007/BF02605383

Smolander A, Ketola RA, Kotiaho T, Kanerva S, Suominen K, Kitunen V (2006) Volatile monoterpenes in soil atmosphere under birch and conifers: effects on soil $\mathrm{N}$ transformations. Soil Biol Biochem 38:3436-3442. doi: 10.1016/j.soilbio.2006.05.019

Stahl PD, Parkin TB (1996) Microbial production of volatile organic compounds in soil microcosms. Soil Sci Soc Am J 60:821-828

Stotzky G, Schenck S (1976) Volatile organic compounds and microorganisms. CRC Crit Rev 4:333-381

Tsuji K, Tsien HC, Hanson RS, DePalma SR, Scholtz R, LaRoche S (1990) 16S ribosomal RNA sequence analysis for determination of phylogenetic relationship among methylotrophs. J Gen Microbiol 136:1-10

Vespermann A, Kai M, Piechulla B (2007) Rhizobacterial volatiles affect the growth of fungi and Arabidopsis thaliana. Appl Environ Microbiol 73:5639-5641. doi: 10.1128/AEM.01078-07

Warneke C, Karl T, Judmaier H, Hansel A, Jordan A, Lindinger W, Crutzen PJ (1999) Acetone, methanol, and other partially oxidized volatile organic emissions from dead plant matter by abiological processes: significance for atmospheric $\mathrm{HO}_{x}$ chemistry. Global Biogeochem Cycles 13:9-17

Wheatley R (2002) The consequences of volatile organic compound mediated bacterial and fungal interactions. Antonie van Leeuwenhoek 81:357-364. doi:10.1023/ A:1020592802234

Wheatley RE, Millar SE, Griffiths DW (1996) The production of volatile organic compounds during nitrogen transformations in soils. Plant Soil 181:163-167. doi:10.1007/ BF00011303

Wheatley R, Hackett C, Bruce A, Kundzewicz A (1997) Effect of substrate composition on production of volatile organic compounds from Trichoderma spp. inhibitory to wood decay fungi. Int Biodeterior Biodegradation 39:199-205

White CS (1988) Nitrification inhibition by monoterpenoids: theoretical mode of action based on molecular structures. Ecology 69:1631-1633. doi:10.2307/1941663

Zhao J, Zhang R (2004) Proton transfer reaction rate constants between hydronium ion $\left(\mathrm{H}_{3} \mathrm{O}^{+}\right)$and volatile organic compounds. Atmos Environ 38:2177-2185. doi:10.1016/ j.atmosenv.2004.01.019 